\title{
Functional MRI in Patients with Band Heterotopia
}

\author{
J. Spreer,* P. Martin,† M. W. Greenlee,‡ R. Wohlfarth,† A. Hammen,† S. M. Arnold,* and M. Schumacher* \\ *Department of Neuroradiol ogy, University Freiburg; †E pilepsiezentrum Kehl-Kork, \\ and $¥$ Neurological Clinic, University Freiburg, Germany
}

Received October 12, 2000; published online May 30, 2001

Functional activation associated with a motor task (fist movements) was studied in three patients with band heterotopias by fMRI. In two patients, additional visual fMRI studies were performed using a flickering checkerboard stimulus. In all patients activation of the outer cortex and of the inner neuronal band could be found during performance of the motor task. Visual stimulation elicited a normal activation pattern without activation of the ectopic neuronal layer in one patient; in another patient activation extended toward the ventricular wall, i.e., along the route of embryonic neuronal migration. The potential participation of ectopic neuronal tissue in physiologic cerebral functions is of clinical impact in patients with neuronal heterotopias suffering from medically intractable seizures prior to epilepsy surgery. pia.

Key Words: fMRI; double cortex; laminar heteroto-

\section{INTRODUCTION}

Laminar or band heterotopias, also called "double cortex syndrome", represent a rare neuronal migration disorder characterized by bilateral ribbons of subcortical gray matter separated from the cortex and from the ventricular walls by white matter (Friede, 1989; Palmini et al., 1991; Barkovich et al., 1989). This developmental anomaly was first described by Matell in 1893 (Matell, 1893). Clinically, patients with band heterotopias present with epileptic seizures, variable degrees of mental retardation, and usually mild neurological signs and symptoms (Palmini et al., 1991; Barkovich et al., 1994).

Little is known about the connectivity and function of the heterotopic neurons. By depth electrode recordings nerve cells within band heterotopias have been shown to exhibit electrogenic patterns similar to those observed in normal cortex (Morell et al., 1992). Metabolic studies with positron emission tomography (PET) revealed normal or even higher glucose utilization in band heterotopias compared to normal cortex (de Volder et al., 1994). However, no activation of periventricular laminar heterotopias during motor and visual tasks was found in a PET activation study by Richardson et al. (1998). I n contrast, only recently Pinard et al. (2000) could demonstrate fMRI activation associated with fingertapping in the subcortical band and the overlying frontal cortex in a single patient with double cortex syndrome.

Patients with disorders of neuronal migration frequently suffer from seizures, which may be medically intractable. Some of these patients may profit from a surgical resection of epileptogenic heterotopias. There fore knowledge of participation of ectopic neuronal tissue in physiologic cerebral functions is of potential clinical impact.

In the present study brain activation associated with a motor task and visual stimulation was studied in three patients with band heterotopias by functional MRI to further elucidate the function of the cortical and subcortical neuronal tissue.

\section{PATIENTS AND METHODS}

Two female patients and one male patient were studied. All patients were informed about the general aims of the study and only participated after giving their informed consent. All patients suffered from seizures since late childhood. Anticonvulsive drugs can affect neuronal activity and cerebral blood flow and thus could influence the results. The clinical data of the patients and the anticonvulsants used during the period of examination are listed in Table 1.

In all patients structural MRI was performed on a 1.5 T scanner (Magnetom Vision) with T1-weighted (TR $650 \mathrm{~ms}$, TE $15 \mathrm{~ms}$, matrix $256 \times 256$ ) and T2weighted (TR 5000 ms, TE 120 ms, matrix $512 \times 512$ ) spinecho sequences and T1-weighted inversion recovery sequences (TR 9994 ms, TE 60 ms, T1 350 ms, matrix $256 \times 256$ ) in two planes (slice thickness $6 \mathrm{~mm}$, interslice gap $0.6 \mathrm{~mm}$, F oV $230 \mathrm{~mm}$ ). The fMRI studies were performed in a second session with multislice gradient-echo echoplanar imaging (EPI) sequences (TE $66 \mathrm{~ms}$; TR $5 \mathrm{~s}$ for the motor paradigm, $4 \mathrm{~s}$ for the visual paradigms; matrix $128 \times 128$, F oV $256 \mathrm{~mm}$ ). For anatomic correlation a T1-weighted 3-D magnetization 
TABLE 1

Summary of Clinical Data and MRI Findings

Patient 1 (B.O.)

19 years, female

9 years

Normal

Age at seizure onset

Neurological/neuro-

ophthalmological findings

Handedness (EI)

IQ

Family history

MRI

Seizure type

Interictal surface EEG

Anticonvulsive drugs
Relearned from left to right 79

No neuropsychiatric disorders Asymmetric band heterotopia

$(1>r)$, normal gyral pattern

GTCS, CPS, SPS, ATS

Background activity 8-9/s; generalized theta-waves; paroxysms of slow waves with spiky discharges LTG, CBZ

Patient 2 (A.M.)

Patient 3 (K.H.)

25 years, female

13 years

Increased reflexes on the right, strabismus, amblyopia (right eye)

Definitely right

76-79

No neuropsychiatric disorders

Asymmetric band heterotopia

$(1>r)$, mild pachygyria, pronounced on the left

GTCS, CPS, PMS

Background activity 5/s; bisynchronous paroxysms of sharp and sharp slow waves

PB, CBZ, VPA
42 years, male

9 years

Pendular nystagmus, mild ataxia

Definitely right

76

No neuropsychiatric disorders

Symmetric band heterotopia, symmetric severe pachygyria

GTCS, CPS, TS, MS

Background activity 6/s; bisynchronous paroxysms of slow waves; multifocal spikes and sharp waves

GP, CBZ, CLZ

Note. Abbreviations: EI, Edinburgh Inventory (Oldfield, 1973); IQ, Intelligence quotient (WAIS). Seizure types: ATS, atonic seizures; CPS, complex partial seizures; GTCS, generalized tonic clonic seizures; MS, myoclonic seizures; SPS, simple partial seizures; PMS, partial motor seizures; TS, tonic seizures. Anticonvulsive drugs: LTG, Lamotrigine; CBZ, Carbamazepine; PB, Phenobarbital; VPA, Sodium val proate; GP, Gabapentin; CLZ, Clonanzepam.

prepared rapid acquisition gradient echo (MP-RAGE) sequence (TR 9, 7 ms, TE 4 ms, TI 300 ms, flip angle $12^{\circ}$ ) with isotropic $1-\mathrm{mm}^{3}$ voxels was acquired.

All three patients performed a motor paradigm consisting of bilateral fist movements versus rest as a control condition. The beginning of every epoch was marked by the acoustically given command start or stop. In two patients additionally the visual system was examined using a flickering checkerboard stimulus. ${ }^{1}$ The paradigms were arranged as block designs with four (motor task) or five (visual task) alternating task and control conditions. Every block consisted of four (motor task) or eight (visual task) measurements. The motor paradigm was explained and trained outside the scanner room prior to the examination.

The functional data were transferred to a PC and evaluated using Brain Voyager software (Göbel et al., 1998). The functional 2-D slices were transformed into functional 3-D volumes by interpolating the original voxels to isotropic 1- $\mathrm{mm}^{3}$ voxels. After 3-D motion correction, temporal smoothing and elimination of linear drifts a correlation analysis with a boxcar reference was performed. The functional maps $(r>0.5)$ were superimposed onto the anatomical data sets and resliced in orthogonal planes. Activation of the inner band was determined by visual inspection in different

\footnotetext{
${ }^{1}$ The third patient was not studied by visual stimulation, because at the time of his examination we did not have a visual stimulation device. All three patients live in different parts of Germany. They came to our institution (E pilepsy center) for short-term evaluation of anticonvulsant therapy. Unfortunately the patient did not agree to return to Freiburg for a further examination.
}

planes and by analysis of the time series in activated areas.

\section{RESULTS}

I maging revealed circumferential broad layers of ectopic neurons in the white matter of the cerebral hemispheres. In the male patient the ectopic neuronal bands were broad and nearly symmetric in both hemispheres. In the two female patients the double cortex was pronounced on the left side. The overlying cer ebral cortex showed generalized severe pachygyric deformation in the male patient. In one of the female patients there was mild pachygyria pronounced in the left hemisphere. In this patient the ectopic band was broader than in the third patient, who had a normal gyral pattern (Figs. 1a-1c).

The motor task resulted in focal cortical activation in both hemispheres in all three patients. The activation in the two female patients was localized in the cortical sensorimotor area around the central sulcus. In the male patient the central sulcus could not be identified morphologically due to the pachygyria. The cortical activation in this subject was localized in an equivalent area in the frontoparietal borderzone. In all three patients additional foci of activation were found in the heterotopic neuronal layer medial and caudal to the activated overlying cortical areas (Figs. 2-4).

Visual stimulation with the flickering checkerboard elicited widespread activation of the cortical visual areas V 1 to $\mathrm{V} 5$ in both patients studied. In the patient with the smallest ectopic layer, activation was re- 
$\mathbf{a}$

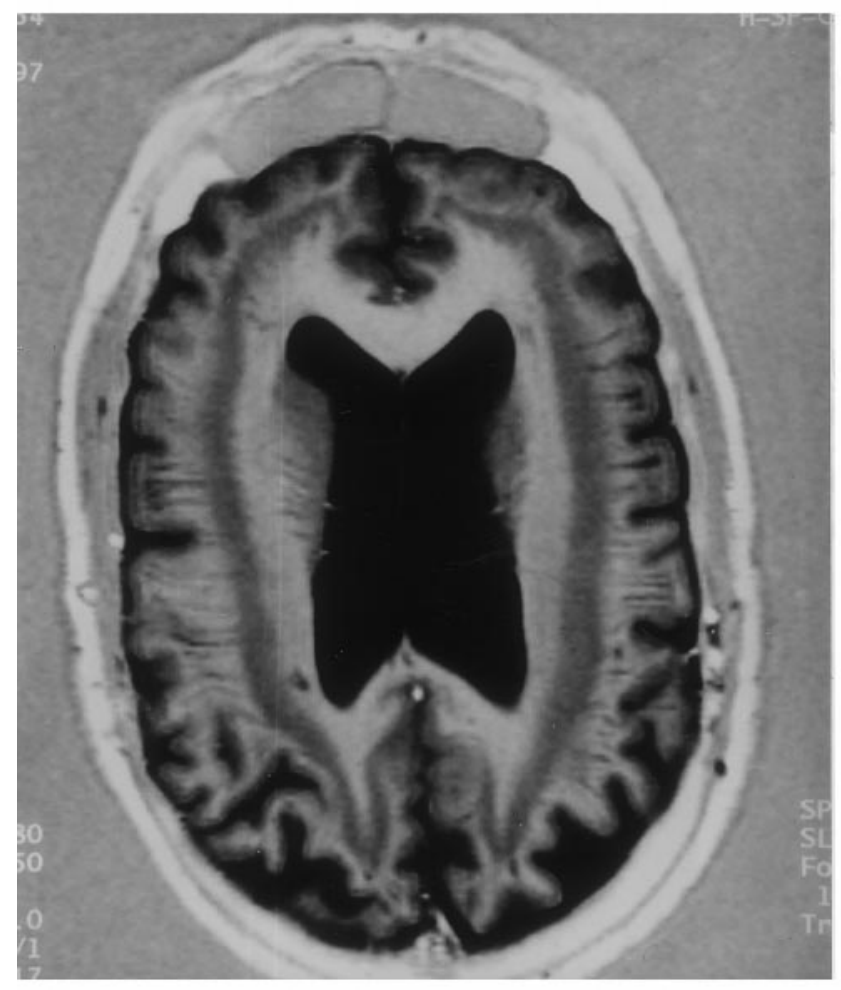

\section{b}

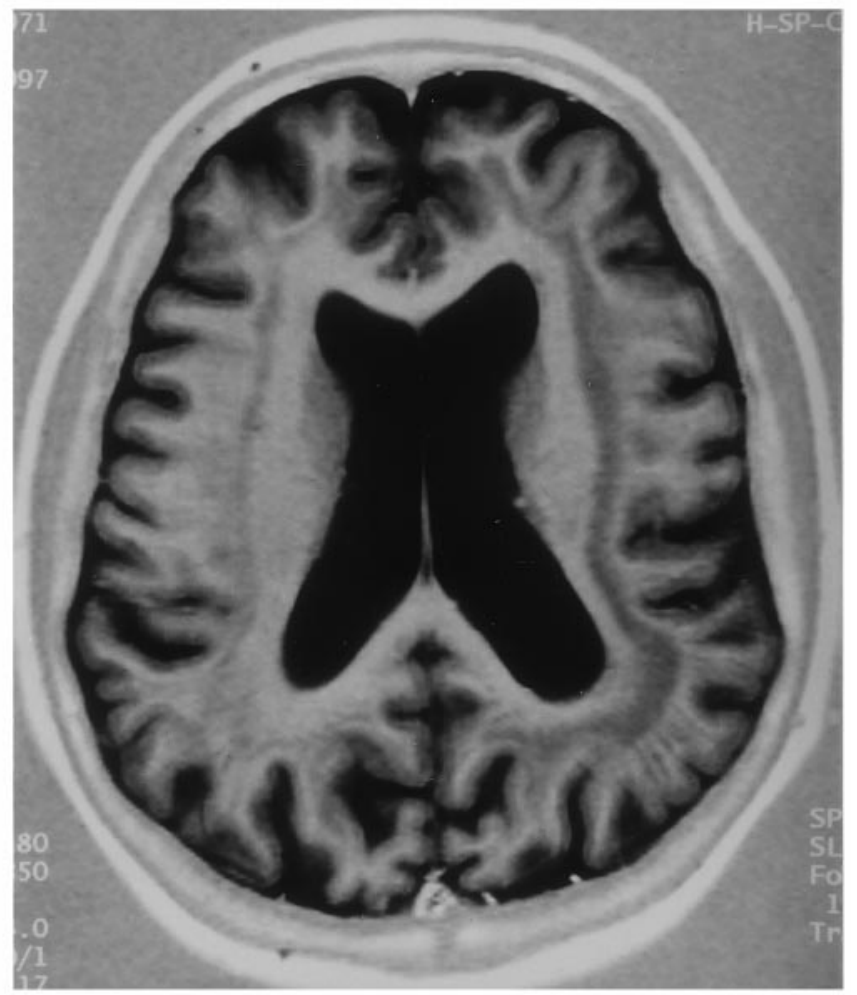

C



FIG. 1. Structural MRIs of the three patients with laminar heterotopias (T1-w. inversion recovery sequence, for technical parameters see text) show bands of ectopic neuronal tissue in the white matter of the cerebral hemispheres which are broader on the left in the both female patients (b, c). Note additional severe generalized pachygyria in the male patient (a) and mild pachygyric deformation in one of the female patients (b); in the third patient (c) the gyral pattern is normal. 


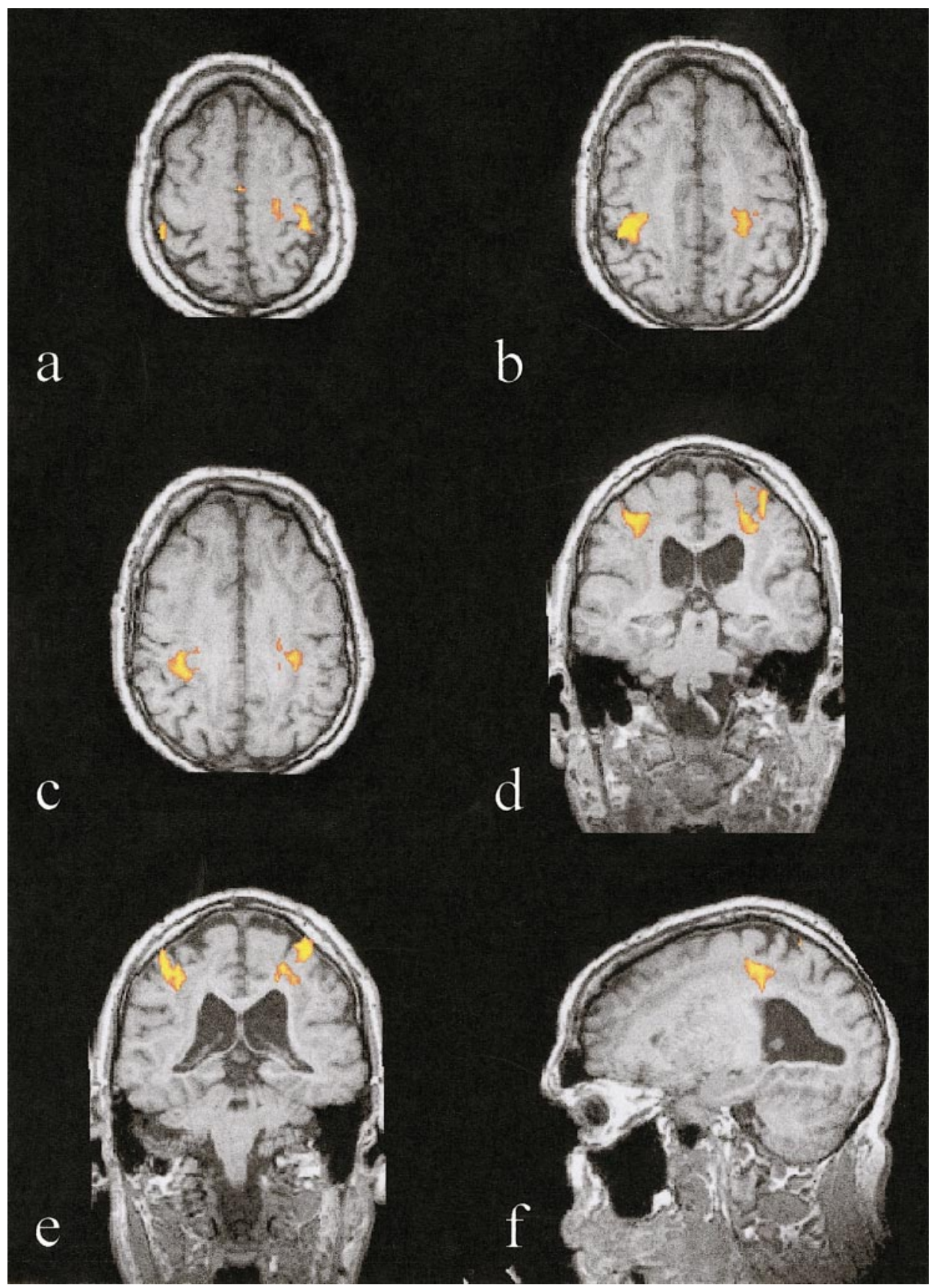

FIGS. 2-4. FMRI activation induced by bilateral fist movements. In all patients the outer primary sensorimotor cortex is activated and additional activation foci are seen in the inner neuronal band. Results are shown from Pat. 1 (Figs. 2a-f), Pat.2 (Figs. 3a-f) and Pat. 3 (Figs. 4a-f). In Figs. $4 \mathrm{~g}$ and $4 \mathrm{~h}$ time courses of activation in the areas marked by yellow squares in Figs. $4 \mathrm{a}$ and $4 \mathrm{c}$ are shown.

stricted to the outer cortex. In the other patient, activation extended from the outer cortex through the white matter toward the wall of the occipital horns (Fig. 5). However, since the ectopic neuronal band faded out, leaving only the outer cortex toward the occipital poles, the two layers in this region were not clearly distinguishable even in the anatomical images. No ectopic neuronal tissue could be identified between the outer cortex and the ventricle, nor were there nod- ular heterotopias in the ventricular wall. In the periventricular "activations" the level of significance was lower and the time-course series less regular than in the outer cortex (Figs. $5 i$ and $5 j$ ).

\section{DISCUSSION}

This fMRI study in patients with band heterotopias revealed task related blood oxygen level dependent 


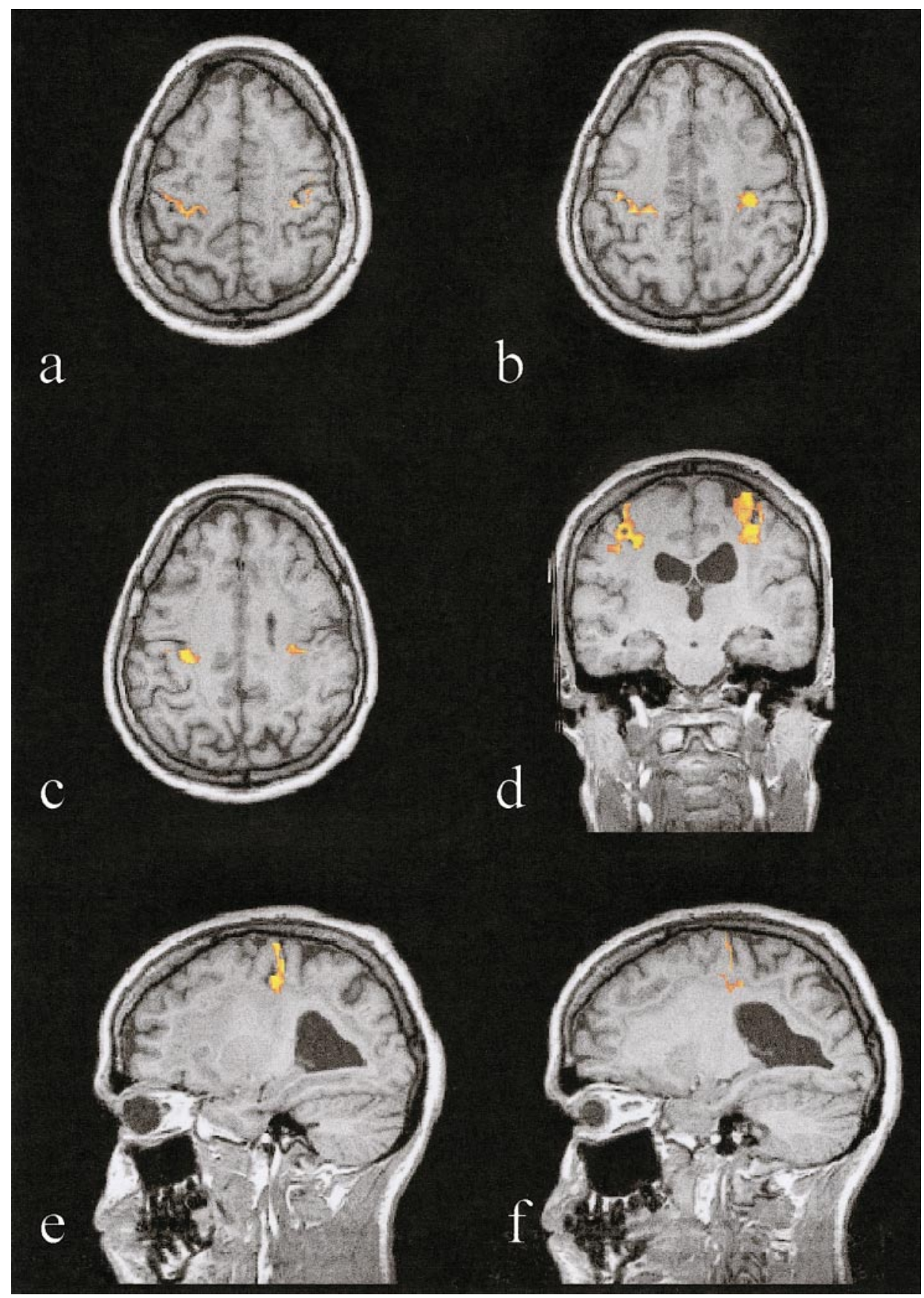

FIGS. 2-4-Continued

(BOLD) contrast in cortical areas adjacent to the heterotopic band and additional activation of the inner ectopic gray layer during performance of the motor task in all subjects. In one of the two patients studied with visual stimulation, activation extended from the outer cortex toward the wall of the occipital horns of the lateral ventricles, i.e., along the embryologic route of neuronal migration.

In the developing brain cortical neurons are generated predominantly in the subventricular zone. Guided by specialized radial glial fibers (Gadisseux and Evrard, 1985; Barkovich et al., 1992) the neurons migrate to their cortical destination site to form the sixlayered neocortex with a peak incidence during the 8th to 24th week of gestation (Rakic, 1972; Volpe, 1995). Periventricular laminar heterotopias result from a migrational arrest during this critical period of brain development. Histologically, the heterotopic band primarily consists of small pyramidal cells, which are randomly arranged in the outer segment and exhibit a 


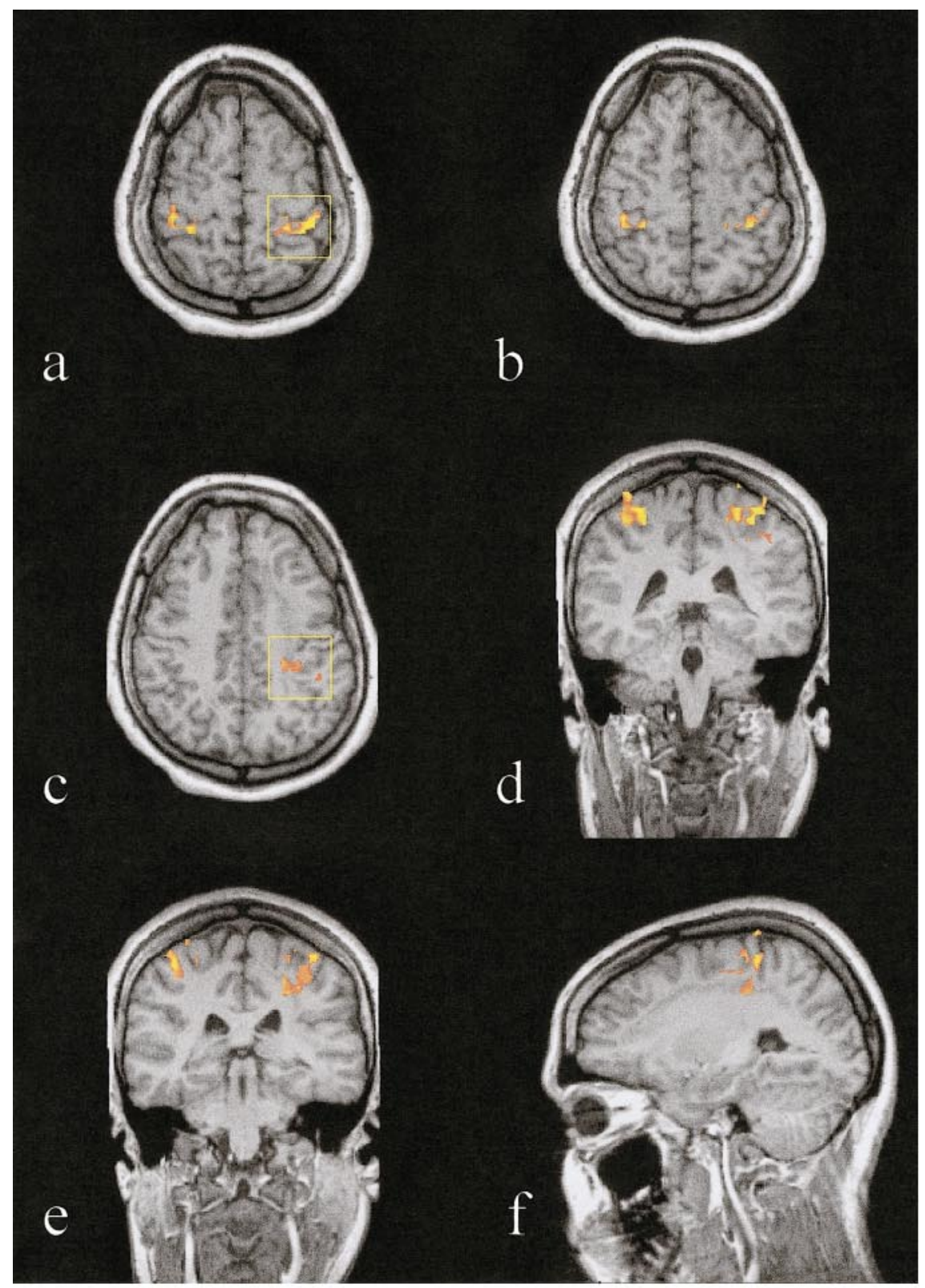

g

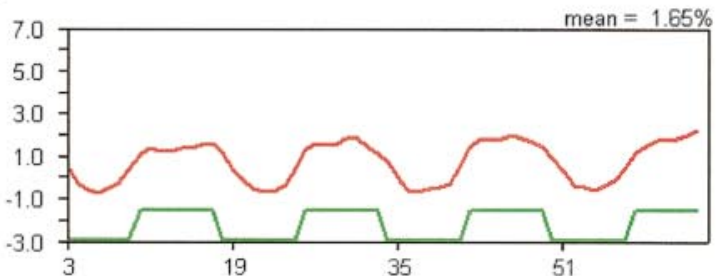

h

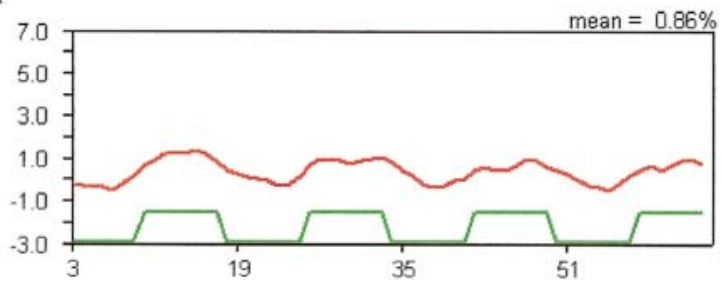

FIGS. 2-4-Continued 

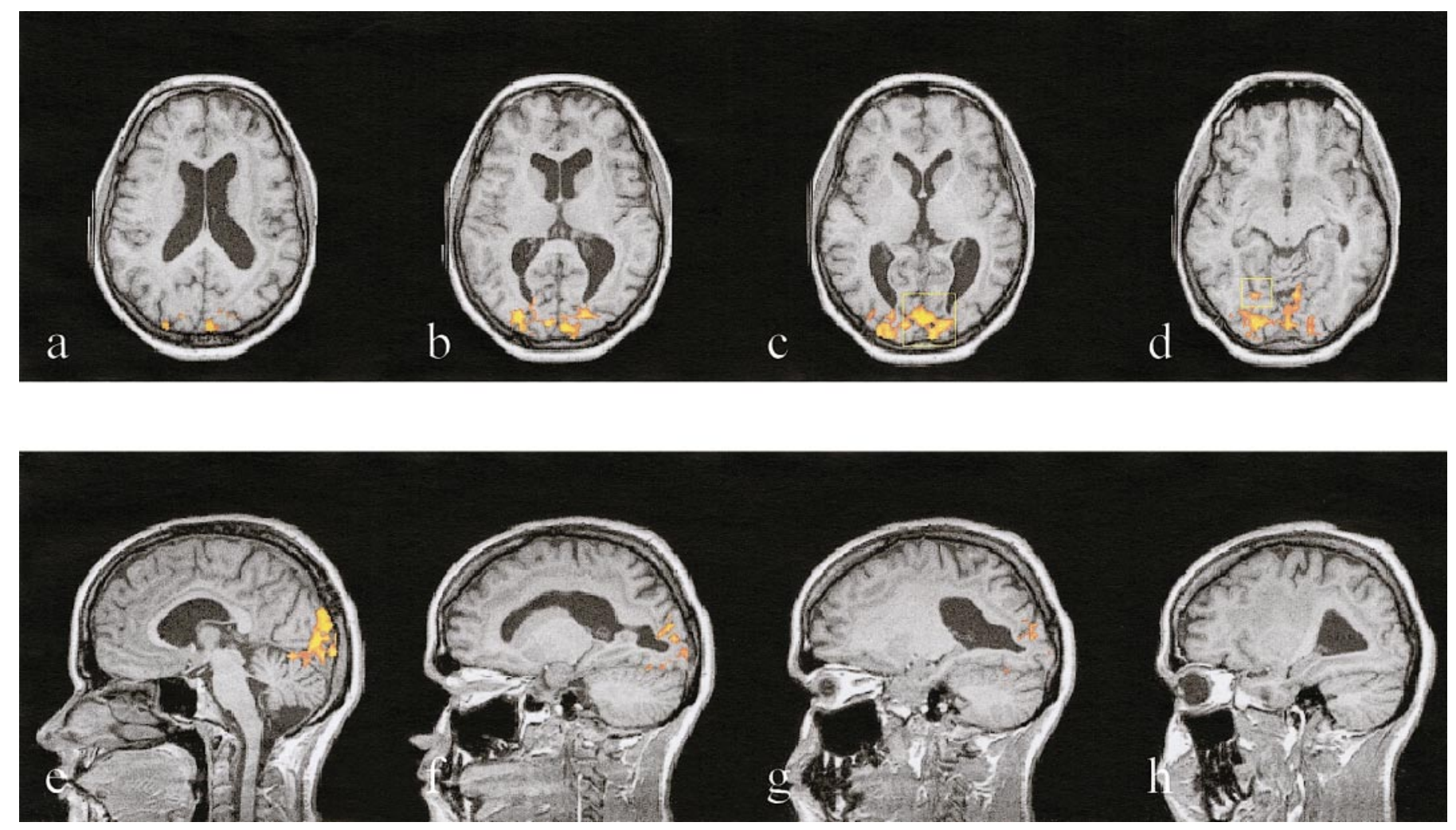

FIG. 5. Axial (a-d) and sagittal (e-h) views of visual activation induced by stimulation with a flickering checkerboard in Pat.2. Some evidence for ectopic activation can be seen in parts of visual cortex. Time courses of activation are shown for the outer cortex (i) and periventricular regions (j).

columnar organization in the inner segment of the band (Harding, 1996). The cortex overlying the heterotopic lamina in most cases has a normal six layered pattern, but an abnormal four layered cortex may be found (Friede, 1989). Macroscopically, it may be normal or exhibit a disturbed gyral pattern (Friede, 1989;



j

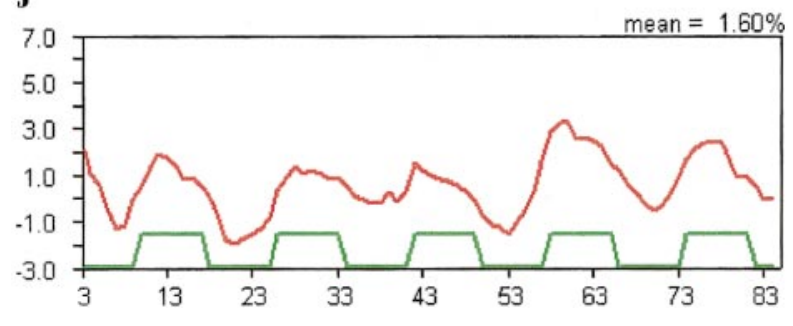

FIG. 5-Continued
Pinard et al., 1994). The distribution and thickness of the heterotopic neuronal band may vary from patient to patient. Frequently it is thickest in the posterior frontal and parietal lobes (Barkovich et al., 1994).

Neuropathological studies suggest that laminar heterotopias and pachygyria/agyria are related developmental disorders. This assumption is supported by genetic findings indicating that band heterotopias and pachygyria/agyria share the same X-linked dominant gene (Pinard et al., 1994). Des Portes et al. (1998) and Gleeson et al. (1998) could map this gene to a small region on the short arm of the X-chromosome and called it doublecortin. The doublecortin gene is highly expressed in neurons and their precursors during fetal brain development. Due to the X-linked inheritance males are affected more severely by mutations of this gene and may develop classic lissencephaly while heterozygous females express milder phenotypes of subcortical band heterotopia. Accordingly, in the single male of our patient sample the double cortex was accompanied by a severe generalized pachygyria. One of the female patients had delineated pachygyric foci and the other had a normal gyral pattern.

Several previous studies point to a participation of heterotopic neuronal tissue in physiologic cerebral functions. Morell et al. (1992) reported on depth elec- 
trode recordings from ectopic cell populations in subcortical heterotopias that revealed electrogenic patterns similar to those observed in the normal cortex in addition to organized epileptiform activity arising from the ectopic gray matter. Several PET studies could demonstrate normal or increased glucose utilization at rest compared with normal cortex in nodular and laminar heterotopias (Miura et al., 1993; Lee et al., 1994; de Volder et al., 1994; Morioka et al., 1999). In a recent $\mathrm{H}_{2}$ (15)O PET activation study patients with band heterotopias showed activation of the cortex overlying the ectopic gray matter, but not of the heterotopic band, while performing visual attention and motor learning tasks (Richardson et al., 1998). However, in some patients with nodular heterotopias task related activation could be detected (Richardson et al., 1998; Calabrese et al., 1995). Only recently, Pinard et al. (2000) were the first to describe activation of the ectopic neuronal band and the overlying cortex during finger-tapping in a patient with double cortex syndrome by fMRI .

In our fMRI study activation of the heterotopic neuronal tissue adjacent to the hand area in sensorimotor cortex could be found in all three patients while performing bilateral fist movements.

In both patients who were studied by visual stimulation the double cortex was broadest in frontoparietal regions and smallest in the occipital lobes adjacent to the outer visual cortex. In one of the two patients activation extended from the outer cortex toward the wall of the occipital horns of the lateral ventricles, although in this region in the anatomical images no ectopic neuronal tissue could be depicted. The extracortical activation pattern resembles the route of the embryologic neuronal migration. Thus, it could be speculated that in this case ectopic neurons, scattered within the macroscopically normal white matter and ventricular wall, participated in the visual task.

The results of animal studies with mutations affecting neuronal migration have shown differences in neuronal function and connectivity depending on the type of genetic alteration. In the reeler mouse mutation, that shows a widespread neuronal migration deficit, abnormally positioned neurons find their normal targets (Stanfield et al., 1979; Nowakowski, 1987). Normal information processing of these connections has been shown in the visual cortex (Dräger, 1976; Lemmon and Pearlman, 1981; Simmons et al., 1983; Nowakowski, 1987), but not in other brain regions of the reeler mouse (Devor et al., 1975; N owakowski, 1987). In other mouse models with disturbances of neuronal migration confined to the hippocampus (Nowakowski and Davis, 1985) or the cerebellum (Nowakowski and Wahlsten, 1985; Nowakowski, 1987) axons of normally positioned neurons do not reach their abnormally seated targets. Thus, the connectivity of heterotopic neurons may differ even within different regions of the same brain. Therefore it seems reasonable that only parts of the ectopic neurons in double cortex syndrome participate in physiologic cerebral functions while others do not.

In the present study, only motor and sensory paradigms were applied. F urther studies are mandatory to elucidate whether the ectopic layer in patients with band heterotopias also participates in "higher" cognitive functions such as language.

The potential participation of heterotopic neurons in physiologic cerebral functions is of clinical impact in patients with migrational disorders suffering from medically intractable seizures. Some of these patients may profit from a surgical resection of the heterotopias. FMRI is a promising tool to study the function of the malformed regions and thus may help to avoid postoperative deficits.

\section{REFERENCES}

Barkovich, A. J ., J ackson, D. E., and Boyer, R. S. 1989. Band heterotopias: A newly recognized neuronal migration anomaly. Radiology 171: 455- 458.

Barkovich, A. J., Gressens, P, and Evrard, P. 1992. Formation, maturation and disorders of brain neocortex. AJ NR Am. J . Neuroradiol. 13: 423- 446.

Barkovich, A. J ., Guerrini, R., Battaglia, G., Kalifa, G., N'Guyen, T., Parmeggiani, A., Santucci, M., Giovanardi-Rossi, P., Granata, T., and D'Incerti, L. 1994. Band heterotopia: Correlation of outcome with magnetic resonance imaging parameters. Ann. Neurol. 36: 609- 617.

Calabrese, P., Fink, G. R., Markowitsch, H. J ., Kessler, J ., Durwen, H. F., Liess, J ., Haupts, M., and Gehlen, W. 1994. Left hemispheric neuronal heterotopia: A PET, MRI, EEG and neuropsychological investigation of a university student. Neurology 44: 302-305.

Des Portes, V., Francis, F., Pinard, J .-M., Desguerre, I., Moutard, M.-L., Snoeck, I., Meiners, L. C., Capron, F., Cusmai, R., Ricci, S., Motte, J., Echenne, B., Ponsot, G., Dulac, O., Chelly, J., and Beldjord, C. 1998. Doublecortin is the major gene causing X-linked subcortical laminar heterotopia (SCLH). Hum. Mol. Genet. 7: 1063-1070.

De Volder, A. G., Gadisseux, J . F. A., Michel, C. J ., Maloteaux, J . M., Bol, A. C., Grandin, C. B., Duprez, T. P., and Evrard, P. 1994. Brain glucose utilization in band heterotopia: Synaptic activity of "double cortex" Pediatr. Neurol. 11: 290-294.

Devor, M., Caviness, V. S., and Derer, P. 1975. A normally laminated afferent projections to an abnormally laminated cortex: Some olfactory connections in the reeler mouse. J. Comp. Neurol. 164: 471- 482.

Dräger, U. C. 1976. Reeler mutant mice: Physiology in primary visual cortex. Exp. Brain. Res. (Suppl. 1): 274-276.

Dräger, U. C. 1981. Observations on the organization of the visual cortex in the reeler mouse. J . Comp. Neurol. 201: 555-570.

Friede, R. L. 1989. Developmental Neuropathology, 2nd ed. Springer, Berlin/Heidelberg/New York.

Gadisseux, J . F., and Evrard, P. 1985. Glial-neuronal relationship in the developing central nervous system. A histochemical-electron microscope study of radial glial cell particulate glycogen in normal and reeler mice and the human fetus. Dev. Neurosci. 7: 12-32.

Gleeson, J . G., Allen, K. M., Fox, J . W., Lamperti, E. D., Berkovic, S., Scheffer, I., Cooper, E. C., Dobyns, W. B., Minnerath, S. R., Ross, M. E., and Walsh, C. A. 1998. Doublecortin, a brain-specific gene mutated in human X-linked lissencephaly and double cortex syndrome, encodes a putative signaling protein. Cell 92: 63-72. 
Goebel, R., Khorram-Sefat, D., Muckli, L., Hacker, H., and Singer, W. 1998. The constructive nature of vision: Direct evidence from functional magnetic resonance imaging studies of apparent motion and motion imagery. Eur. J . Neurosci. 10: 1563-1573.

Harding, B. 1996. Gray Matter Heterotopia. In Dysplasias of Cere bral Cortex and Epilepsy (R. Guerrini, F. Andermann, R. Canapicchi, B. G. Zifkin, P. Pfanner, Eds.), pp. 81- 88. Raven-Lippincott, Philadel phia.

Lee, N., Radtke, R. A., Gray, B., Burger, P. C., Montine, T. J ., De Long, G. R., Lewis, D. V., Oakes, W. J ., Friedman, A. H., and Hoffman, J . M. 1994. Neuronal migration disorders: Positron emission tomography correlations. Ann. Neurol. 35: 290-297.

Lemmon, V., and Pearlman, A. L. 1981. Does laminar position determine the receptive field properties of cortical neurons? A study of corticotectal cells in area 17 of the normal mouse and the reeler mutant. J . Neurosci. 1: 83-93.

Matell, M. 1893. Ein Fall von Heterotopie der grauen Substanz in beiden Hemisphären des Großhirns. Archive der Psychiatrié und Nervenkrankheiten. 25: 124-136.

Miura, K., Watanabe, K., Maeda, N., Matsumoto, A., Kumagai, T., Ito, K., and Kato, T. 1993. Magnetic resonance imaging and positron emission tomography of band heterotopia. Brain Dev. 15: 288-290.

Morioka, T., Nishio, S., Sasaki, M., Y oshida, T., Kuwabara, Y., Ohta, M., and Fukui, M. 1999. Functional imaging in periventricular nodular heterotopia with the use of FDG-PET and HMPAOSPECT. Neurosurg. Rev. 22: 41- 44.

Morioka, T., Nishio, S., Sasaki, M., Yoshida, T., Kuwabara, Y., Nagamatsu, T., and Fukui, M. 1999. Functional imaging in schizencephaly using FDG-PET and HMPAO-SPECT. Neurosurg. Rev. 22: 99-101.

Morrell, F., Whisler, W. W., Hoeppner, T. J ., Smith, M. C., Kanner, A. M., PierreLouis, S. J ., Chez, M. G., and Hasegawa, H. 1992. Electrophysiology of heterotopic gray matter in the "double cortex" syndrome. Epilepsia 33/S3: 76 (Abstract).

Nowakowski, R. S., and Davis, T. L. 1985. Dendritic arbors and dendritic excrescences of abnormally positioned neurons in area
CA3c of mice carrying the mutation "hippocampal lamination defect." J . Comp. Neurol. 239: 267-275.

Nowakowski, R. S., and Wahlsten, D. 1985. Anatomy and development of the hippocampus and dentate gyrus in shaker-short tail (sst) mutant mouse. Anat. Rec. 211: 140A

Nowakowski, R. S. 1987. Basic concepts of CNS development. Child. Dev. 58: 568-595.

Oldfield, R. C. 1971. The assessment and analysis of handedness: The Edinburgh inventary. Neuropsychologia 9: 97-113.

Palmin, A., Andermann, F., Aicardi, J ., Dulac, O., Chaves, F., Ponsot, G., Pinard, J . M, Goutieres, F., Livingston, J ., Tampieri, D., Andermann, E., and Robitaille, Y. 1991. Diffuse cortical dysplasia, or the "double cortex" syndrome: The clinical and epileptic spectrum in 10 patients. Neurology 41: 1656-1662.

Pinard, J .-M., Motte, J ., Chiron, C., Brain, R., Andermann, E., and Dulac, O. 1994. Subcortical laminar heterotopia and lissencephaly in two families: A single X-linked dominant gene. J . Neurol. Nerosurg. Psychiatry. 57: 914-920.

Pinard, J ., Feydy, A., Carlier, R., Perez, N., Pierot, L., and Burnod, Y. 2000. Functional MRI in double cortex: functionality of heterotopia. Neurology 54: 1531-1533.

Rakic, P. 1972. Mode of cell migration to the superficial layers of fetal monkey neocortex. J . Comp. Neurol. 145: 61- 83.

Ricci, S., Cusmai, R., Fariello, G., Fusco, L., and Vigevano, F. 1992. Double Cortex. A neuronal migration anomaly as a possible cause of Lennox-Gastaut syndrome. Arch. Neurol. 49: 61- 64.

Richardson, M. P., Koepp, M. J ., Brooks, D. J ., Coull, J . T., Grasby, P., Fish, D. R., and Duncan, J. S. 1998. Cerebral activation in malformations of cortical development. Brain 121: 1295-1304.

Simmons, P. A., and Pearlman, A. L. 1983. Receptive-field properties of transcallosal visual cortical neurons in the normal and reeler mouse. J . Neurophysiol. 50: 838-848.

Standfield, B. B., Caviness, V. S., and Cowan, W. M. 1979. The organization of certain afferents to the hippocampus and dentate gyrus in normal and reeler mice. J . Comp. Neurol. 185: 461- 484.

Volpe, J. J. 1995. Neurology of the Newborn, 3rd ed. Saunders, Philadel phia L ondon/Toronto/Montreal/Sydney/Tokyo. 